\title{
Subcutaneous immunoglobulin therapy: a new option for patients with primary immunodeficiency diseases
}

This article was published in the following Dove Press journal:

Biologics:Targets and Therapy

23 August 2012

Number of times this article has been viewed

\section{Lisa Kobrynski}

Department of Pediatrics, Emory University, Atlanta, GA, USA
Correspondence: Lisa Kobrynski Allergy/lmmunology Section, Emory Children's Center 2015 Uppergate Drive, Atlanta, GA 30322 USA

Tel +l 4047273575

Fax + I 4047275045

Email lkobryn@emory.edu

\begin{abstract}
Since the 1950s, replacement of immunoglobulin G using human immunoglobulin has been the standard treatment for primary immunodeficiency diseases with defects in antibody production. These patients suffer from recurrent and severe infections, which cause lung damage and shorten their life span. Immunoglobulins given intravenously (IVIG) every 3-4 weeks are effective in preventing serious bacterial infections and improving the quality of life for treated patients. Administration of immunoglobulin subcutaneously (SCIG) is equally effective in preventing infections and has a lower incidence of serious adverse effects compared to IVIG. The tolerability and acceptability of SCIG has been demonstrated in numerous studies showing improvements in quality of life and a preference for subcutaneous immunoglobulin therapy in patients with antibody deficiencies.
\end{abstract}

Keywords: primary immunodeficiency diseases, subcutaneous immunoglobulin, immunoglobulin G

\section{Background}

Primary immunodeficiency diseases (PIDD) are a group of over 150 disorders due to defects in critical pathways involved in host defense against infection and immune regulation. PIDD are due to single-gene defects, the causative mutation having been identified in more than 140 of these disorders. The underlying immune defect can impair innate immunity or adaptive immunity, but all patients with PIDD have an increased susceptibility to infection. More than 50\% of PIDD are due to defects in antibody production (Table 1$).{ }^{1}$ In addition to recurrent and severe bacterial infections, patients with antibody deficiencies also have an increased frequency of autoimmune disease, inflammatory disorders, and lymphoproliferative disorders. Life expectancy is reduced and recurrent infections cause significant morbidity and disability due to complications from chronic lung disease, inflammatory bowel disease and autoimmune disorders.

Since the 1950s, replacement of serum immunoglobulin G (IgG) with human immune globulin products has been the standard of treatment for patients with hypo/ agammaglobulinemia and a significant impairment of specific antibody formation. ${ }^{2}$ The first human immunoglobulin (IG) products were administered intramuscularly and were effective in decreasing mortality. However, it was difficult to maintain physiologically normal levels of serum IgG due to limitations in the dose of IG that could be administered. Intramuscular injections were painful and early IG products contained aggregates of IgG that caused serious adverse effects. Slow subcutaneous infusions of IG (SCIG) were used in the early 1980s to treat antibody deficiency, but the acceptance 
Table I Primary immunodeficiencies: antibody deficiencies

\begin{tabular}{|c|c|c|}
\hline Disorder & $\begin{array}{l}\text { Gene } \\
\text { (if known) }\end{array}$ & $\begin{array}{l}\text { IgG replacement } \\
\text { indicated? }\end{array}$ \\
\hline \multicolumn{3}{|l|}{ Agammaglobulinemia } \\
\hline X-linked agammaglobulinemia & Btk & Yes \\
\hline$\mu$ heavy chain deficiency & IGHM & Yes \\
\hline $\lg \alpha$ deficiency & CD79A & Yes \\
\hline $\lg \beta$ deficiency & CD79B & Yes \\
\hline B-cell linker protein & BLNK & Yes \\
\hline \multicolumn{3}{|c|}{ Common variable immune deficiency } \\
\hline Immune co-stimulator protein & ICOS & Yes \\
\hline CDI9 deficiency & CDI9 & Yes \\
\hline CD20 deficiency & CD20 & Yes \\
\hline TACI deficiency & TNFRSFI3B & Yes \\
\hline BAFF receptor deficiency & TNFRSFI3C & Yes \\
\hline CVID & Unknown & Yes \\
\hline \multicolumn{3}{|l|}{ Other antibody deficiencies } \\
\hline Selective $\lg \mathrm{A}$ deficiency & Unknown & No \\
\hline $\lg G$ subclass deficiency & Unknown & $\begin{array}{l}\text { If recurrent } \\
\text { infections }\end{array}$ \\
\hline Specific antibody deficiency & Unknown & \\
\hline $\begin{array}{l}\text { Transient hypogammaglobulinemia } \\
\text { of infancy }\end{array}$ & Unknown & \\
\hline \multicolumn{3}{|c|}{ Other PIDD with antibody deficiency } \\
\hline HyperlgM syndrome $X$-linked & $\mathrm{CD} 40 \mathrm{~L}$ & Yes \\
\hline Autosomal recessive & AID, UNG & Yes \\
\hline $\begin{array}{l}\text { Severe combined immune } \\
\text { deficiency }\end{array}$ & Various & Yes \\
\hline Wiskott-Aldrich syndrome & WASP & Yes \\
\hline Ataxia-telangiectasia syndrome & ATM & Yes \\
\hline Reticular dysgenesis & $\mathrm{AK} 2$ & Yes \\
\hline DiGeorge syndrome & $\begin{array}{l}22 q|| .2 /|0 p| 3 \\
\text { deletion }\end{array}$ & $\begin{array}{l}\text { Only for patients } \\
\text { with low IgG }\end{array}$ \\
\hline
\end{tabular}

Note: Data based on IUIS classification of primary immune deficiencies.'

Abbreviations: IgG, immunoglobulin G; Btk, Bruton's tyrosine kinase; TACl, transmembrane activator and calcium-modulating cyclophilin ligand interactor; TNFRSF, tumor necrosis factor receptor super family; BAFF, B-cell activating factor; CVID, common variable immune deficiency; CD40L, CD40 ligand; AID, activating inducing cytidine deaminase; UNG, uracil DNA glycosylase; WASP, Wiskott-Aldrich syndrome protein; ATM, ataxia-telangiectasia mutated; AK2, adenylate kinase 2.

of this therapy was limited by the length of time for infusion and the volumes that could be infused..$^{3-6}$ In the $1980 \mathrm{~s}$, the development of IgG products for intravenous administration (IVIG) that contained only monomers of $\mathrm{IgG}$, allowed patients to receive sufficient quantities of $\operatorname{IgG}$ to achieve serum levels in the physiologic range with fewer side effects. These products could be given monthly, and with higher levels of $\mathrm{IgG}$, further decreased morbidity from infection and increased survival, as well as overall quality of life.

In 1991, Gardulf et al reported the use of infusion pumps to administer SCIG as a rapid infusion. ${ }^{7}$ For the past two decades, SCIG has been the treatment of choice for patients with antibody deficiencies in Sweden, while IVIG has been the standard treatment in the United States (US). Since 2006, when the United States Food and Drug Administration (FDA) approved the first SCIG, the use of SCIG to treat patients with PIDD and antibody deficiency has been steadily increasing. ${ }^{8}$ SCIG has been demonstrated to be effective and safe and has important advantages of tolerability, ease of administration and quality of life (QOL) improvements over IVIG. The development of higher concentration IgG products, improved delivery devices, and alternate methods of delivery will further increase the use of SCIG for the treatment of PIDD with antibody deficiency.

\section{Immune globulin preparation}

IG products used for intravenous (IV) or subcutaneous (SC) administration are collected from human donors at plasma collection centers. The pooled plasma from more than 5000 donors is treated using modified Cohn-Oncley cold ethanol fractionation, which separates the plasma into IgG, albumin, and clotting factors. Plasma donors are screened for high risk behaviors and the plasma fractions are tested for Hepatitis B surface antigen, HIV-1/HIV-2 antibodies, and Hepatitis $\mathrm{C}$ virus (HCV) antibody. Most products also test plasma pools using $\mathrm{HIV}-1$ and $\mathrm{HCV}$ nucleic acid testing. After Cohn fractionation, the IgG may be further purified using anion exchange chromatography and (in some products) caprylate precipitation. The immunoglobulin plasma pool undergoes additional viral inactivation steps such as heat treatment, enzyme treatment, solvent/detergent treatment, low $\mathrm{pH}$ incubation, and/or nanofiltration. These steps have been shown to reduce the viral load for enveloped viruses (eg, HIV, West Nile virus, Hepatitis C virus) by $10^{12}$ to $10^{16}$, nonenveloped viruses (eg, Hepatitis A virus, parvovirus) by $10^{5}$ to $10^{10}$, and prions (Creuzfeldt-Jakob). ${ }^{9-15}$

Despite differences in viral inactivation steps and the use of different agents as stabilizing or buffering agents, all IG products contain 97\%-98\% IgG monomers with trace amounts of IgM, as well as IgG specific antibodies against a broad spectrum of bacterial and viral pathogens. IG products approved for SC administration contain varying concentrations of IgA (37-50 mcg/mL). ${ }^{9,11,12}$ Currently available preparations of IVIG are available as 5\% (5 g/100 mL) or $10 \%(10 \mathrm{~g} / 100 \mathrm{~mL})$ solutions. ${ }^{9-11}$ Some are lyophilized and need to be reconstituted before administration, but the majority of products are available as liquid (ready to use) preparations. Three of the products approved by the FDA for SC administration in PIDD (all $10 \% \mathrm{IG}$ ) also have approval for IV administration. One SCIG product approved solely for SC administration (20\% IG) is manufactured using the same process as the IVIG products. Table 2 describes the characteristics of IG products approved by the FDA for SC administration. 
Table 2 Subcutaneous immune globulin preparations (US) - properties and characteristics

\begin{tabular}{|c|c|c|c|c|}
\hline Product & IgG concentration & IgA content & Stabilizer & Viral inactivation \\
\hline \multirow[t]{3}{*}{ Gammagard liquid } & $100 \mathrm{mg} / \mathrm{mL}$ & $37 \mathrm{mcg} / \mathrm{mL}$ & Glycine & Solvent/detergent \\
\hline & & & & Nanofiltration \\
\hline & & & & Low pH/temperature \\
\hline \multirow[t]{3}{*}{ Gammaked $^{T M}$} & $100 \mathrm{mg} / \mathrm{mL}$ & $46 \mathrm{mcg} / \mathrm{mL}$ & Glycine & Low pH \\
\hline & & & & Caprylate precipitation \\
\hline & & & & Depth filtration \\
\hline \multirow[t]{3}{*}{ Gamunex-C } & $100 \mathrm{mg} / \mathrm{mL}$ & $46 \mathrm{mcg} / \mathrm{mL}$ & Glycine & Low pH \\
\hline & & & & Caprylate precipitation \\
\hline & & & & Depth filtration \\
\hline \multirow[t]{3}{*}{ Hizentra $^{\circledR}$} & $200 \mathrm{mg} / \mathrm{mL}$ & $<50 \mathrm{mcg} / \mathrm{mL}$ & L-proline & Low pH \\
\hline & & & & Nanofiltration \\
\hline & & & & Depth filtration \\
\hline
\end{tabular}

Note: Data drawn from package inserts. ${ }^{9-12}$

\section{Pharmacokinetics}

During SC administration the IgG product is infused into the $\mathrm{SC}$ space. After receiving IVIG the peak serum concentration occurs 15 minutes after the infusion and the $\mathrm{IgG}$ is rapidly distributed into the extravascular space. Typically, infusions of IVIG cause a rapid increase in serum IgG with a sharp drop off in serum levels over the following 48 hours, and a linear decline in levels thereafter. Previously, the half-life of IgG following IVIG administration was estimated to be 21 to 28 days. ${ }^{16,17}$ Newer IG products have a longer serum half-life of 35 to 37 days. ${ }^{9-12}$ In clinical practice, the trough serum IgG level measured immediately before infusion of IVIG is used to adjust dosing of the product. Administration of $\mathrm{IgG}$ through the $\mathrm{SC}$ route results in slower absorption of $\mathrm{IgG}$, the peak serum IgG level occurring at 2 to 4 days postinfusion. ${ }^{18-20}$ Administration of weekly SCIG doses results in steady state pharmacokinetics with little fluctuation in IgG levels. During the clinical trials of SCIG products in the US, manufacturers were required by the FDA to show equivalence of SCIG products with IVIG products based on measurements of the IgG concentration from the area under the curve (AUC), which represents cumulative IgG levels from peak to trough. Pharmacokinetic studies showed that the dose of SCIG needed to match the AUC levels of IgG from IVIG was found to be $137 \%$ of the IV dose. ${ }^{21}$ Clinical trials of SCIG in Europe compared the efficacy of SCIG with IVIG based on achieving a comparable serum trough level. ${ }^{22}$ Subjects with antibody deficiencies on IVIG therapy received the equivalent total monthly dose of IgG, which was divided into weekly doses and administered subcutaneously. Even without an increase in total monthly IgG dose, the steady state IgG levels were $11 \%$ higher with SCIG than the trough IgG levels with monthly IVIG. ${ }^{22,23}$ In one North American clinical trial, serum IgG levels (steady state) with
SCIG rose $32 \%$ over the trough IgG levels with IVIG. ${ }^{21}$ More frequent dosing with $\mathrm{SCIG}$ results in variations of serum $\mathrm{IgG}$ between 100-200 mg/dL from peak to trough IgG levels, ${ }^{18,24}$ compared to a decline of $55 \%$ for the serum IgG from the peak IgG level following an IV infusion to the trough IgG level obtained prior to the next IV infusion 28 days later. ${ }^{25}$ The steady state kinetics of SCIG is related to smaller, more frequent dosing, as well as slower systemic absorption. The absence of a rapid spike in serum IgG levels postinfusion, may be one of the contributing factors to the less frequent occurrence of severe systemic reactions following infusion of SCIG compared to IVIG. ${ }^{26}$ The kinetics of serum IgG levels on SCIG may also account for the observation by patients receiving weekly $\mathrm{SC}$ infusions, that they no longer experience fatigue and malaise - the "trough effects" - which typically occurred the week prior to their IVIG infusion. ${ }^{27-29}$

\section{Efficacy}

Survival of patients with antibody deficiencies has increased dramatically since the introduction of IgG replacement therapy, and the efficacy of IVIG and SCIG in preventing serious bacterial infections is well established. The main measure of efficacy of IG in most clinical trials is the annual rate of serious bacterial infections (eg, pneumonia, sepsis, meningitis). However, monthly infusions of IVIG are also associated with a decrease in the incidence of other bacterial infections, including bronchitis, otitis media, and sinusitis. ${ }^{30-35}$ Clinical trials of SCIG administered weekly have shown equal efficacy compared to IVIG in preventing serious bacterial infections in patients with antibody deficiency. ${ }^{36}$ In several studies in the US and Europe using an open-label prospective model, the reported annual rates of serious bacterial infections was less than 0.1. ${ }^{19-22,37-40}$ Secondary outcomes included: the occurrence of other infections (eg, sinusitis, otitis media); 
days in hospital; days on antibiotics; and days missed from work/school because of infection. SCIG administered weekly shows equivalent efficacy to IVIG in preventing other infections, and is effective in preventing hospitalizations due to infection, and minimizing days missed from work/school and days on antibiotics (Table 3 ).

The optimal dosing for IG replacement therapy in PIDD is still not known. While serum trough IgG levels have been used to monitor and guide therapy, other variables should be considered when using serum trough IgG levels to direct dosing of IG replacement. A meta-analysis of the incidence of pneumonia in PIDD patients on IVIG replacement therapy reviewed 17 clinical studies conducted in the US, Canada, Europe, Argentina, and the Middle East. ${ }^{41}$ It showed that the incidence of pneumonia decreased by $27 \%$ for each $100 \mathrm{mg} / \mathrm{dL}$ increase in the IgG trough level. None of the studies, however, evaluated the efficacy of serum IgG trough levels above $1000 \mathrm{mg} / \mathrm{dL}$, so it is unknown whether the effects of IgG replacement therapy reach a plateau above this level. A more recent retrospective review of a series of 105 patients with common variable immune deficiency (CVID) and X-linked agammaglobulinemia (XLA) reported that a greater proportion of XLA patients who had IgG trough levels $>1000 \mathrm{mg} / \mathrm{dL}$ experienced 0 bacterial infections per year. ${ }^{42}$

Recurrent respiratory infections are thought to contribute to the development of chronic lung disease with bronchiectasis and/or interstitial lung disease, which cause substantial morbidity in patients with antibody deficiency due to PIDD. Previous studies have suggested that using higher doses
(600 $\mathrm{mg} / \mathrm{kg} / \mathrm{month})$ of IVIG and maintaining serum IgG trough levels in the physiologic range $(650-1000 \mathrm{mg} / \mathrm{dL})$ has an effect on improving comorbidity due to chronic lung disease. ${ }^{43-45}$ The meta-analysis by Orange et $\mathrm{al}^{41} \mathrm{did}$ not evaluate the efficacy of serum IgG trough levels on the development of bronchiectasis or chronic lung disease, so the optimal dosing of IG replacement needed to prevent these complications is still unknown. It is clear, however, that higher IgG trough levels decreases hospitalization due to bacterial infection, ${ }^{46}$ and can decrease the rates of other infections as well. ${ }^{47}$ Interestingly, this meta-analysis did not demonstrate a significant difference in the effect of the level of the IgG trough on the incidence of pneumonia between subjects with CVID and those with XLA. This is noteworthy, as recent discussions have suggested that optimal IgG trough levels may be higher for patients with CVID, based on their baseline serum IgG levels prior to starting IG replacement therapy. ${ }^{48-50}$ Another meta-analysis of seven studies of weekly SCIG infusions showed a statistically significant relationship between increasing serum IgG levels and decreasing annual infection rates (not serious bacterial infections). ${ }^{51}$ The mean IgG levels in subjects in these studies ranged from $810 \mathrm{mg} / \mathrm{dL}$ to $1250 \mathrm{mg} / \mathrm{dL} .{ }^{51}$ Again, the efficacy of SCIG on the reduction in infection rates appeared to correlate with the mean serum IgG levels regardless of the underlying PIDD (XLA or CVID). In contrast, a retrospective survey of infection rates in 90 patients with CVID or XLA showed that patients with XLA required a significantly higher IgG trough level to remain infection-free. ${ }^{42}$

Table 3 Effectiveness of IG SC in preventing infections/efficacy of IG SC - clinical trials

\begin{tabular}{|c|c|c|c|c|c|c|c|c|c|}
\hline Year & Location & $\mathbf{N}$ & $\begin{array}{l}\text { Mean dose } \\
\text { (mg/kg/week) }\end{array}$ & Mean IgG & $\begin{array}{l}\text { SBI annual } \\
\text { rate }\end{array}$ & $\begin{array}{l}\text { Other } \\
\text { infection }\end{array}$ & $\begin{array}{l}\text { Hospital } \\
\text { days* }\end{array}$ & $\begin{array}{l}\text { Missed } \\
\text { days* }\end{array}$ & $\begin{array}{l}\text { Antibiotic } \\
\text { days* }\end{array}$ \\
\hline $2006^{22}$ & EU & 52 & 100 & 922 & 0.04 & 4.3 & $|2 /|$ & NR & NR \\
\hline $2006^{21}$ & US & 51 & 158 & 1040 & 0.04 & 4.4 & 0.23 & 3.7 & 120.2 \\
\hline $2010^{37}$ & US & 51 & NR & 1100 & 0.03 & 3.4 & $4 d(I)$ & 4.5 & NR \\
\hline $2010^{20}$ & US & 32 & $\begin{array}{l}\text { I.37x } \\
\text { IVIG dose }\end{array}$ & 1140 & 0 & 4.1 & $N R$ & NR & NR \\
\hline $2010^{38}$ & US & 38 & $\begin{array}{l}\text { I.53x } \\
\text { IVIG dose }\end{array}$ & 1250 & 0 & 2.8 & 0.2 & 2.1 & 48.5 \\
\hline $2011^{40}$ & US & 47 & 182.6 & 1202 & 0.067 & 4.1 & 0 & 4 & 37.3 \\
\hline $201 I^{39}$ & EU & 46 & 118.5 & 810 & 0 & 5.2 & 0.95 & 5.2 & 66.6 \\
\hline \multirow[t]{3}{*}{$2011^{19}$} & EU & 18 & I29.9 (children) & 778 & 0 & 4.8 & 1.7 & 7.7 & 30.6 \\
\hline & & 5 & II 3.7 (teens) & 814 & 0 & 5.2 & 0 & 1.8 & 0.4 \\
\hline & & 28 & I 4.3 (adults) & 832 & 0 & 5.5 & 0.63 & 4.3 & 59.4 \\
\hline
\end{tabular}

Note: *Days per subject per year.

Abbreviations: N, number of subjects; NR, not reported; IG, immunoglobulin; SC, subcutaneous, IVIG, intravenous immunoglobulin. 
A dose of 400 to $600 \mathrm{mg} / \mathrm{kg}$ given every 3 to 4 weeks, or $100-200 \mathrm{mg} / \mathrm{kg}$ weekly is recommended for IVIG therapy for PIDD with antibody deficiency. The effect of body mass index (BMI) on serum trough levels is unclear. In a retrospective review of 107 patients comparing the annual dose of IG and the serum trough IgG levels, no relationship was seen even after correction for BMI. ${ }^{52}$ However, Berger et al found that subjects with a BMI greater than $30 \mathrm{~kg} / \mathrm{m}^{2}$ required a greater dose adjustment for SCIG in order to match the AUC of IVIG. ${ }^{53}$ Therefore, titration of dosing is based on the serum trough levels as well as the clinical response. Clinical factors including: the patient's underlying PIDD (eg, CVID, XLA), the IgG level at diagnosis, the IgA level, the presence of bronchiectasis, cytopenias or enteropathy should be taken into consideration when dosing IVIG or SCIG. Individuals with XLA, CVID with IgA deficiency, and those with complications of their PIDD appear to require higher doses of IVIG/SCIG regardless of the serum trough level. ${ }^{42,54}$

\section{Administration of SCIG}

Administration of IG products by the SC route for patients with antibody deficiencies is gaining increasing acceptance in the US and other countries. ${ }^{5-57}$ There are currently four products licensed by the FDA for SC administration in patients over 2 years of age (Table 2). Dosing of SCIG for PIDD patients already receiving IVIG should be based on their current dose of IVIG as well as their serum trough levels. The manufacturer's recommendations for dosing in the US are to multiply the current IVIG dose by 1.37 (for $10 \%$ IG products) or 1.53 (for $20 \%$ IG product), and divide by the number of weeks between infusions. For example, a patient receiving $40 \mathrm{~g}$ of IVIG every 4 weeks would receive: $40 \mathrm{~g} \times 1.37=54.8 \mathrm{~g} \div 4=13.7 \mathrm{~g}$ per week (or $40 \mathrm{~g} \times 1.53=51.2 \mathrm{~g} \div 4=15.3 \mathrm{~g}$ per week for $20 \% \mathrm{SCIG})$. This increase in dosing maintains the serum IgG levels to approximate the AUC kinetics seen in patients receiving IVIG. However, clinical trials in Europe demonstrated an increase in serum IgG levels over the trough IgG levels when the equivalent IV monthly dose was given weekly by the SC route, with no dose correction used. The weekly SC dose would be calculated by taking the current monthly IVIG dose and dividing by the treatment interval (eg, 3 or 4 weeks).22,23 Once SCIG therapy has been started, the weekly dose should be adjusted based on trough/steady state IgG levels and the patient's clinical response. The initial dose of SCIG is usually given 7 to 10 days after the last dose of IVIG. For patients who have not yet started IG replacement therapy, two approaches have been suggested.
The first would be to give a single infusion of IVIG $(1 \mathrm{~g} / \mathrm{kg})$ followed by weekly SCIG doses (100 mg/kg/week). ${ }^{21} \mathrm{An}$ alternate regimen administers $100 \mathrm{mg} / \mathrm{kg} / \mathrm{dose}$ of SCIG daily for 5 days followed by weekly infusions. ${ }^{39}$

The European experience with rapid infusions of SCIG demonstrated that rates up to $40 \mathrm{~mL} /$ hour using two to four sites to administer $40 \mathrm{~mL}(6.4 \mathrm{~g})$ per infusion were welltolerated in PIDD patients. ${ }^{58-60}$ In the US, the clinical trials for the first FDA approved SCIG product (16\%) used a maximum of $15 \mathrm{~mL}$ per site and a maximal rate of $20 \mathrm{~mL} /$ site/hour. $^{21}$ Subsequent studies increased the dose per site to $30 \mathrm{~mL}$ and the rate of infusion to $30 \mathrm{~mL} /$ hour/site..$^{20,38,40}$ The package inserts for the $10 \%$ and $20 \%$ SCIG products recommend limiting the volume of the IG to $20 \mathrm{~mL}$ per site for PIDD patients with a body weight less than $40 \mathrm{~kg}$ and $30 \mathrm{~mL}$ per site in patients weighing more than $40 \mathrm{~kg}$. The suggested initial infusion rates are $15 \mathrm{~mL} / \mathrm{site} / \mathrm{hour}(<40 \mathrm{~kg})$ or $20 \mathrm{~mL} / \mathrm{site} /$ hour ( $>40 \mathrm{~kg}$ ), increasing to $20 \mathrm{~mL} /$ site/hour and $30 \mathrm{~mL} / \mathrm{site} /$ hour, respectively. ${ }^{9-12}$ Multiple sites can be infused simultaneously using sites on the abdomen, thighs, upper arms, or lower back, with most infusions able to be completed in less than 90 minutes. Patients may choose to use more infusion sites, thus shortening the overall infusion time as less volume is infused per site, or they may prefer to infuse the product more slowly in order to tolerate larger volumes per site and use fewer sites. Although the recommended dosing interval is weekly, more frequent dosing (daily or 2 to 3 times per week) may improve serum IgG levels further and result in fewer infections. Shapiro reported a retrospective analysis of 104 patients with PIDD receiving SCIG using either rapid push administration or an infusion pump. ${ }^{61} 71 \%$ of patients chose to use the rapid push method and received an average dose of $32.11 \mathrm{~g} /$ month given in doses approximately three times per week. The volume of SCIG per site ranged from 3 to $20 \mathrm{~mL}$ and was given over 5-20 minutes ( $1 \mathrm{~mL} /$ minute) using a 25 -gauge butterfly needle and a $12 \mathrm{~mL}$ syringe. The serum IgG levels and rate of systemic adverse events were similar between the two methods.

SCIG is infused using needle sets designed for SC infusions. Needles are mounted at a $90^{\circ}$ angle to plastic wings or a clear plastic disk to facilitate proper insertion of the needle into the subcutaneous fat, and to help keep the needles in place during the infusion. Numerous infusion sets are available, with needle sizes from 24-27 gauge, and 6, 9, 12 and $14 \mathrm{~mm}$ lengths. The shorter needle lengths should only be used in very young children or individuals with very lean body mass, as the use of shorter needles is associated with increased leakage of IG and irritation at the infusion site. ${ }^{62}$ 
The type of tubing set selected will depend on the number of sites and infusion pumps used. Tubing sets are available with single, bifurcated, trifurcated, quadfurcated, and five leg branches attached to a single trunk, which can be connected to the syringe or infusion pump. The SCIG product should be allowed to reach room temperature prior to infusion. The product is drawn up into one or more syringes depending on the amount to be infused, and the number and the type of infusion pumps being used. The infusion needle set tubing is connected to the syringe and the tubing is primed prior to insertion of the needle. Some infusion pumps use an IV bag or "cassette," which is filled with the SCIG product and connected to the pump. A number of different infusion pumps have been used for administration of SCIG. Most of these are syringe pumps which will accept a $50 \mathrm{~mL}$ syringe and some can be programmed to set different infusion rates. Pumps designed for IV infusion often do not have sufficient power to infuse into the SC space which generates a much higher resistance to flow compared to IV infusions.

The skin sites are cleansed prior/to needle insertion with an antiseptic such as alcohol. Some patients prefer to use a topical anesthetic cream to numb the skin prior to SC needle insertion, however this is not generally needed since there is usually minimal discomfort. The needle should be placed at a $90^{\circ}$ angle to the skin and inserted through the dermal layer so that the tip rests in the subcutaneous fat. After insertion patients are advised to gently pull back on the syringe plunger and examine the tubing for any blood return. The presence of blood in the tubing may mean that the needle is in the intravascular space and should be removed to avoid injection of SCIG intravenously. If the needle placement is correct, the same procedure is repeated for the other sites and the infusion pump is turned on. If multiple sites are used, it is important to monitor the amount of swelling at each site during the infusion. Due to occasional differences in resistance in the SC tissue, one site may receive an excessive volume of SCIG causing a local reaction. If this occurs, the tubing for that site can be clamped so that no further flow will occur and the remaining site(s) will continue to receive the SCIG.

It is important that the patient and/or their caregiver (if the patient is incapable of self-administration) receive thorough instruction in the administration of SCIG and demonstrate the correct technique for administration to their physician and/ or nursing staff. Various teaching materials, including online videos of patients performing SCIG infusions, are available on the internet and through patient organizations. ${ }^{63-66}$ While these materials are useful tools for helping to educate patients and their families, they should not be used as a replacement for directly observed therapy and teaching by trained medical staff. In addition, CSL Behring (King of Prussia, PA) has created a web-based program for nursing staff to receive training on the administration of SCIG through the Starting Hizentra Administration with Resources and Education program. ${ }^{67}$

\section{Side effects}

While both IVIG and SCIG infusions increase serum IgG levels and are effective in preventing many bacterial and viral infections, systemic adverse events occur less frequently with SCIG. The most common side effects of IVIG infusions include headache, fever, fatigue, vomiting, chills, dizziness, and hives. Drug-related and temporarily related adverse events have been reported to occur in 9\%-29\% of IVIG infusions. ${ }^{68-71}$ Headaches occurring after IVIG infusion and lasting 24-72 hours are one of the most common side effects. Serious adverse events have been noted in up to $20 \%$ of patients receiving IVIG, although many of these adverse events may have been unrelated to the study drug. ${ }^{70}$ The majority of adverse events occur during or within 48 hours of the infusion, and may be related to the rapid increase in serum IgG concentration. Most of the data regarding adverse events with IVIG administration come from clinical trials of new products where subjects are generally not permitted to use premedication to prevent adverse reactions. One prospective review of 459 PIDD patients who were self-infusing IVIG in the home showed an overall reaction rate of $0.8 \%$; however, $50 \%$ of these patients routinely used premedication prior to infusion to prevent infusion reactions. ${ }^{72}$

In contrast, serious systemic adverse events rarely occur with SCIG infusions. Most studies report a rate of less than $1 \%,{ }^{21,38,60,73,74}$ although one study reported a higher rate of $3.3 \%$ for serious adverse events. ${ }^{36}$ Local reactions with redness, pain, or swelling at the site of infusion were reported by the majority of subjects participating in the US trials. Most of these local reactions were considered mild, with only slight swelling and redness, or moderate, with some blanching of the swelling and a ring of erythema. The incidence of these local reactions, however, decreases over time and very few patients discontinue SCIG therapy due to local reactions. ${ }^{21,22}$ One additional consideration is the complication of using indwelling catheters for vascular access to facilitate administration of IVIG. In young children, the elderly, and patients with other medical conditions, monthly venous access can become increasingly difficult. Indwelling catheters have been used to provide a reliable portal for administration of IVIG however, due to the risks of infection this practice is discouraged..$^{57}$ 
In 1999, the FDA required manufacturers of IVIG products licensed in the US to add a "black box" warning to advise patients of the risk of acute renal failure. ${ }^{75}$ The development of acute renal failure was most associated with IVIG products that contained sucrose, products that were given in large doses in older patients, and in patients with renal insufficiency prior to the infusion. ${ }^{76}$ To date, renal insufficiency has not been noted after SCIG administration and the products currently available in the US for SC administration do not contain sucrose.

Thrombotic events (TE) occurring after IVIG infusion using high doses to treat patients with neurologic conditions have been thought to be related to the increase in serum viscosity sometimes seen after IVIG infusion. ${ }^{77} \mathrm{~A}$ large retrospective review of TE after IG infusion demonstrated a significant increase in the risk of TE with Octagam ${ }^{\circledR}$ (Octapharma, Lachen, Switzerland; IVIG), Vivaglobin ${ }^{\circledR}$ (CSL Behring, Kankakee, IL; SCIG) with an odds ratio of 2.03 and 3.56, respectively. ${ }^{78}$ The risk of TE appears to be related to increased factor XI procoagulant activity, possibly related to specific manufacturing processes. ${ }^{78,79}$ This risk is further increased in older patients and those with a hypercoagulable state. ${ }^{78}$ Vivaglobin $^{8}$ is no longer manufactured for use in the US, and Octagam ${ }^{\circledR}$, initially removed from the market, has now been reintroduced following changes in the manufacturing process intended to minimize the procoagulant activity of the product.

Two additional important adverse events that have been seen after IVIG therapy are hemolysis and transfusion-related acute lung injury. Hemolysis may be triggered by the presence of red blood cell antibodies and is more likely to occur in patients with neurologic disorders. Transfusion-related acute lung injury reactions are rare and have not been reported in PIDD patients receiving IVIG. ${ }^{76}$

Many of the acute adverse events appear to be related to the rate of IV infusion, and may be attenuated by slowing the rate of infusion in addition to use of pretreatment with antihistamines and acetaminophen. Pretreatment before IVIG infusion with antihistamines, acetaminophen, and sometimes systemic steroids is widely used, but is rarely needed with SCIG infusions.

\section{Quality of life}

Numerous studies have demonstrated the acceptability of SCIG, as well as improvements in overall QOL measures (see Table 4). ${ }^{27,29,37,39,60,73,81-83}$ Studies have used standardized validated health-related QOL questionnaires such as the Child Health Questionnaire - Parent Form 50 (CHQ-PF50), the Short Form 36-item Health Survey (SF-36), and the Life Quality Index (LQI). The subjects and the parents of pediatric subjects completed these questionnaires before starting SCIG, and again after 6-12 months. The CHQ-PF50 and SF-36 provide a subjective assessment of: physical functioning, physical and psychological limitations, self-esteem, general health perceptions, the impact of PIDD treatment on the parent(s)'s and child's emotional and physical well-being, and the impact of the patient's health on the family. ${ }^{27}$ The LQI measures the patient's satisfaction with all aspects of their $\operatorname{IgG}$ replacement therapy including ease of administration, convenience, and costs. ${ }^{80} \mathrm{~A}$ summary of results for these QOL measures from clinical trials of SCIG conducted in Europe and North America is presented in Table $4 .{ }^{27,29,37,39,60,73,81-83}$ Uniformly, patients reported some improvements in QOL measures, most often in the impact of SCIG treatment as measured by improvements in their feeling of general well-being, as well as in improvements in the impact of their illness on both their own and their family's activities. This improvement in QOL is reflected in the observation that the majority of patients receiving IVIG infusions in the hospital or clinic reported a preference for SCIG over IVIG therapy. Patients who had been receiving IVIG infusions at home also reported a preference for SCIG. ${ }^{29}$

\section{Selection of patients}

Numerous clinical trials and decades of experience using SCIG therapy for PIDD with antibody deficiency have confirmed the safety and efficacy of SCIG., ${ }^{41-23,27,36-40,59,84,93}$ SC administration has been the predominant route of administration in Sweden for more than 15 years, but the majority of patients in the US continue to receive IG through the IV route. A survey of physician members of the American Academy of Allergy Asthma and Immunology in 2005-2006, prior to FDA licensure of IG product for SC administration in the US, reported that $76 \%$ of physicians believed that SCIG and IVIG were of equal efficacy for the treatment of PIDD. ${ }^{57}$ Despite the general acceptance of the safety and efficacy of SCIG, its use to treat PIDD is still not widespread, some larger centers reporting that only $10 \%-15 \%$ of their patients on IG therapy receive it subcutaneously. ${ }^{50}$

There are several practical considerations to take into account when selecting the route of IG administration for a patient with PIDD. Any patient with an antibody deficiency requiring $\operatorname{IgG}$ replacement therapy could be considered a candidate for SCIG. Advantages of this route of administration include: ease of administration, no need for vascular access, ability to infuse at home, low rate of systemic adverse events, and steady state IgG levels (no trough or "wear off" effect). SCIG has also been used in situations in which IVIG may have an unacceptable rate of side effects, the kinetics of IV administration are unfavorable, or when venous access is 
Table 4 Quality of life studies in PIDD patients switching to SCIG therapy

\begin{tabular}{|c|c|c|c|}
\hline Year: country & Comparison groups & Outcomes & Preference \\
\hline $\begin{array}{l}1995 \text { Sweden, } \\
\text { Norway, Denmark }{ }^{73}\end{array}$ & $\begin{array}{l}\text { SCIG hospital vs } \\
\text { SCIG at home }\end{array}$ & $\begin{array}{l}\text { Non-standardized questionnaires: high level of general satisfaction } \\
\text { with SCIG at home, increased feeling of independence }\end{array}$ & $\begin{array}{l}92 \% \text { preferred SCIG } \\
\text { over IMIG or IVIG }\end{array}$ \\
\hline 2002 Sweden $^{60}$ & SCIG at home & High level of satisfaction with rapid SCIG infusion & $\begin{array}{l}92 \% \text { continued rapid } \\
\text { SCIG }\end{array}$ \\
\hline 2004 Europe $^{27}$ & $\begin{array}{l}\text { SCIG at home vs } \\
\text { IVIG hospital }\end{array}$ & $\begin{array}{l}\text { Statistically significant improvements in general health perception, } \\
\text { parental emotional impact, family activities, and global health. } \\
\text { (CHQ-PF50) vitality, mental health and social functioning (SF-36) and } \\
\text { improved satisfaction with IG therapy (Life Quality Index) for SCIG }\end{array}$ & $73 \%$ preferred SCIG \\
\hline $\begin{array}{l}2006 \\
\text { North America }{ }^{29}\end{array}$ & $\begin{array}{l}\text { A: SCIG at home vs } \\
\text { IVIG hospital } \\
\text { B: SCIG home vs } \\
\text { IVIG at home }\end{array}$ & $\begin{array}{l}\text { Statistically significant improvements in physical limitations, general } \\
\text { health, vitality, health transition, LQI/treatment satisfaction (A); } \\
\text { general health (B) SCIG }\end{array}$ & $\begin{array}{l}81 \%(\mathrm{~A}), 69 \%(\mathrm{~B}) \\
\text { preferred SCIG }\end{array}$ \\
\hline 2006 Germany $^{82}$ & $\begin{array}{l}\text { SCIG at home vs IVIG } \\
\text { hospital/clinic }\end{array}$ & $\begin{array}{l}\text { Non-standardized questionnaire mailed to patients: treatment } \\
\text { satisfaction higher with SCIG, perceived increase in inconvenience } \\
\text { of SCIG for patients on IVIG }\end{array}$ & $\begin{array}{l}\text { I/33 patients went } \\
\text { back to IVIG during } \\
\text { study }\end{array}$ \\
\hline 2008 Sweden $^{81}$ & $\begin{array}{l}\text { SCID at home vs } \\
\text { IVIG hospital }\end{array}$ & $\begin{array}{l}\text { Statistically significant improvements in mental health, change in } \\
\text { health, family activities and global health at } 6 \text { months (CHQ-PF50) }\end{array}$ & $\begin{array}{l}\text { All subjects preferred } \\
\text { home } \mathrm{SCIG}\end{array}$ \\
\hline $\begin{array}{l}2010 \\
\text { North America }{ }^{37}\end{array}$ & $\begin{array}{l}\text { SCIG at home vs } \\
\text { IVIG clinic }\end{array}$ & $\begin{array}{l}\text { Statistically significant improvements in general health } \\
\text { at } 6 \text { and } 12 \text { months and vitality at } 6 \text { months }\end{array}$ & Not reported \\
\hline 2010 & SCID at home vs & Statistically significant improvements in bodily pain, general & $92 \%$ preferred SCIG \\
\hline Germany ${ }^{83}$ & IVIG hospital & $\begin{array}{l}\text { health perception, vitality (SF-36), family activities, parental } \\
\text { emotional and time, general health }\end{array}$ & $\begin{array}{l}83 \% \text { preferred } \\
\text { home treatment }\end{array}$ \\
\hline $\begin{array}{l}2011 \\
\text { Germany }\end{array}$ & $\begin{array}{l}\text { SCID at home vs } \\
\text { IVIG hospital }\end{array}$ & $\begin{array}{l}\text { Health-related Quality of Life, LQI improved in SCIG, } \\
\text { significant increase in score for convenience }\end{array}$ & $\begin{array}{l}80 \% \text { preferred } \\
\text { SCIG }\end{array}$ \\
\hline
\end{tabular}

Abbreviations: PIDD, primary immunodeficiency diseases; SCIG, subcutaneous immunoglobulin; CHQ-PF50, Child Health Questionnaire - Parent Form 50; IVIG, intravenous immunoglobulin; IMIG, intramuscular immunoglobulin; LQI, Life Quality Index.

difficult. Clinical trials and case series have demonstrated the safety of SCIG in infants, pregnant women and IgA deficient patients with anti-IgA antibodies in the serum. ${ }^{84-86}$ Patients with hypogammaglobulinemia due to gastrointestinal losses may benefit from more frequent, smaller doses of $\mathrm{IgG}$. At this time, there is very limited experience using SCIG for the treatment of autoimmune or inflammatory disorders requiring very large doses of IG to achieve very high IgG concentrations needed to treat these conditions. ${ }^{87,88}$

There are some situations in which SCIG may not be the preferred route of administration including: if the patient or caregiver is physically unable to perform the infusion or requires nursing assistance, if there is severe thrombocytopenia with excessive bruising and bleeding at the sites of infusion, or in the setting of severe skin disease in which it would be difficult to place the SC needles. The patient's lifestyle and personal preferences should also be considered. Patients may choose to return to IVIG therapy after receiving SCIG as a result of: local side effects (pain, swelling, redness at the infusion sites), anxiety regarding needle sticks, or a preference for performing their infusion less frequently (monthly versus weekly) with less needle sticks. In addition, physicians should ensure that the patient will adhere to the treatment regimen. Patients who do not reliably attend clinic visits or complete their medical treatment plan may benefit from the additional supervision received during monthly clinic or home visits to receive IVIG.

\section{New SCIG products}

Since the first SCIG product (Vivaglobin ${ }^{\circledR}, 16 \%$ ) was introduced to the US in 2006, the only major change has been the concentration of $\operatorname{IgG}$. At least two $10 \% \operatorname{IgG}$ products previously licensed for IV administration have received FDA approval for SC administration (Gammagard liquid [Baxter Healthcare Corporation, West Lake Village, CA], Gamunex-C [Talecris Biotherapeutics, Research Triangle Park, NC]) and another 10\% IgG product (Gammaked ${ }^{\mathrm{TM}}$; Kedrion Biopharma, Cambridge, MA) has been introduced for both IV and SC administration. A $20 \%$ IgG product (Hizentra ${ }^{\circledR}$; CSL Behring) solely for SC administration is also now available in the US. The $20 \%$ IgG product is advantageous in that the infusion volume is smaller, potentially decreasing the number of sites required to administer the SCIG. Alternate methods of administration: rapid SC push, giving SCIG daily, biweekly, and bimonthly have also been reported..$^{60,61}$

$\mathrm{SC}$ injection of recombinant human hyaluronidase has been shown to facilitate the dispersion of IG-injected SC, allowing patients to infuse larger volumes of IG into a single site on a monthly basis. ${ }^{89}$ Clinical trials are ongoing to evaluate the safety and efficacy of injection of a $10 \%$ IgG product 
following injection of recombinant human hyaluronidase using doses and rates equivalent to monthly IVIG treatment. Several abstracts presented at the American Academy of Allergy Asthma and Immunology meeting, March 2012, reported preliminary results from clinical trials demonstrating that injection of $\operatorname{IgG~} 10 \%$ every 3-4 weeks at doses comparable to monthly IVIG (320 mg/kg/month - $1000 \mathrm{mg} / \mathrm{kg} / \mathrm{month})$ using a single SC site and infused at rates up to $300 \mathrm{~mL} / \mathrm{hr}$ were well tolerated..$^{90,91}$ The rate of local reaction was slightly higher than traditional SCIG and the rate of systemic reactions was comparable to SCIG but significantly lower than seen with IVIG. ${ }^{92,93}$ In addition, the pharmacokinetics of IG infused with hyalurdonidase SC were comparable to IVIG, with therapeutic IgG trough levels and good bioavailability. ${ }^{92}$ The annual rate of infection for patients in the study was lower than seen for patients on SCIG or IVIG. ${ }^{93}$

\section{Conclusion}

Significant improvements have occurred in the treatment of PIDD with antibody deficiency in the past 60 years since the first patients were treated with IG therapy. Treatment with IVIG significantly decreased mortality and morbidity and increased life expectancy, as patients had increased serum IgG levels and fewer serious bacterial infections. SCIG therapy confers several additional benefits for PIDD patients including: maintenance of serum IgG levels in the physiologic range with "steady state" kinetics, reduction in the rate of infections, lower rates of systemic adverse effects, and important benefits for the patient's QOL. PIDD patients have a number of choices for their IG treatment regimen. This allows the practitioner to tailor therapy to fit an individual's medical condition, lifestyle. The development of new SCIG products that facilitate the administration of larger volumes of IG delivered subcutaneously will offer additional options for long term IgG replacement therapy.

\section{Disclosure}

The authors report no conflicts of interest in this work.

\section{References}

1. Al-Herz W, Bousfiha A, Casanova JL, et al. Primary immunodeficiency diseases: an update on the classification from the International Union of Immunological Societies Expert Committee for Primary Immunodeficiency. Front Immunol. 2011;2(54):1-26.

2. Bruton OC. Agammaglobulinemia. Pediatrics. 1952;9:722-728.

3. Berger M, Cupps TR, Fauci AS. Immunoglobulin replacement therapy by slow subcutaneous infusion. Ann Intern Med. 1980;93(1):55-56.

4. Roord JJ, van der Meer JW, Kuis M, et al. Home treatment in patients with antibody deficiency by slow subcutaneous infusion of gammaglobulin. Lancet. 1982;1(8273):689-690.

5. Ugazio AG, Duse M, Re R, Mangili G, Burgio GR. Subcutaneous infusions of gammaglobulins in management of agammaglobulinaemia. Lancet. 1982;319(8265):226.
6. Welch MJ, Stiehm ER. Slow subcutaneous immunoglobulin therapy in a patient with reactions to intramuscular immunoglobulin. J Clin Immunol. 1983;3(3):285-286.

7. Gardulf A, Hammarstrom L, Smith CL. Home treatment of hypogammaglobulinemia with subcutaneous gammaglobulin by rapid infusion. Lancet. 1991;338(8760):162-166.

8. fda.gov [homepage on the Internet]. January 9, 2006 approval letter for Vivaglobin. Silver Spring, MD: US Food and Drug Administration [updated 2011 April 8]. Available from: http:/www.fda.gov/ BiologicsBloodVaccines/BloodBloodProducts/Approvedproducts/ licensedproductsBLAs/fractionatedplasmaproducts/UCM070367.htm. Accessed April 24, 2012.

9. Gammagard liquid ${ }^{\circledR}$ (immune globulin infusion, human, 10\%) [prescribing information]. West Lake Village, CA: Baxter Healthcare Corporation; 2012.

10. Gammaked ${ }^{\mathrm{TM}}$ (immune globulin injection, human, 10\%) [prescribing information]. Research Triangle Park, NC: Talecris Biotherapeutics, Inc.; 2011.

11. Gamunex-C (immune globulin injection, human, 10\%) [prescribing information]. Research Triangle Park, NC: Talecris Biotherapeutics, Inc.; 2010.

12. Hizentra (immune globulin subcutaneous, human, $20 \%$ liquid) [prescribing information]. Kankakee, IL: CSL Behring LLC; 2011.

13. Lee DC, Stenland CJ, Hartwell RC, et al. Monitoring plasma processing steps with a sensitive Western Blot assay for the detection of the prion protein. J Virol Methods. 2000;84(1):77-89.

14. Stenland CJ, Lee DC, Brown P, et al. Partitioning of human and sheep forms of the pathogenic prion protein during the purification of therapeutic proteins from human plasma. Transfusion. 2002;42:1497-500.

15. Strucki M, Boschetti N, Schafer W, et al. Investigations of prion and virus safety of a new liquid IVIG product. Biologicals. 2008;36(4): 239-247.

16. Mankarious S, Lee M, Fischer S, et al. The half-lives of IgG subclasses and specific antibodies in patients with primary immunodeficiency who are receiving intravenously administered immunoglobulin. J Lab Clin Med. 1988;112(5):634-640.

17. Waldman TA, Strober W, Blaese RM. Metabolism of immunoglobulins. Prog Allergy. 1969:13:1-110.

18. Waniewski I, Gardulf A, Hammarström L. Bioavailability of gammaglobulin after subcutaneous infusions in patients with common variable immunodeficiency. J Clin Immunol. 1994;14(2):90-97.

19. Borte M, Pac M, Serban M, et al. Efficacy and safety of Hizentra, a new $20 \%$ immunoglobulin preparation for subcutaneous administration, in pediatric patients with Primary Immunodeficiency. J Clin Immunol. 2011;31:752-761.

20. Wasserman RL, Irani AM, Tracy J, et al. Pharmacokinetics and safety of subcutaneous immune globulin (human), 10\% caprylate/ chromatography purified in patients with primary immunodeficiency disease. Clin Exp Immunol. 2010;161:518-526.

21. Ochs HD, Gupta S, Kiessling P, Nicolay U, Berger M. Safety and efficacy of self-administered subcutaneous immunoglobulin in patients with primary immunodeficiency diseases. J Clin Immunol. 2006;26(3):265-273.

22. Gardulf A, Nicolay U, Asensio O, et al. Rapid subcutaneous IgG replacement therapy is effective and safe in children and adults with primary immunodeficiencies - a prospective, multi-national study. J Clin Immunol. 2006;26(2):177-185.

23. Desai SH, Chouksey A, Poll J, Berger M. A pilot study of equal doses of $10 \%$ IGIV given intravenously or subcutaneously. J Allergy Clin Immunol. 2009;124:854-856.

24. Vivaglobin ${ }^{\circledR}$ (immune globulin subcutaneous, human, 16\%) [prescribing information]. Kankakee, IL: CSL Behring, LLC; 2010.

25. Ochs HD, Pinciaro PJ. The Octogam study group, Octogam 5\% an intravenous $\mathrm{IgG}$ product is efficacious and well tolerated in subjects with primary immunodeficneicy diseases. J Clin Immunol. 2004;24: 309-314.

26. Ballow M. Safety of IGIV therapy and infusion related adverse events. Immunol Res. 2007;38:122-132. 
27. Gardulf A, Nicolay U, Math D, et al. Children and adults with primary antibody deficiencies gain quality of life by subcutaneous IgG selfinfusions at home. J Allergy Clin Immunol. 2004;114:936-942.

28. Immune Deficiency Foundation. Treatment Experiences and Preferences of Patients with Primary Immune Deficiency Diseases: First National Survey 2002. June 20, 2003. Available from: http:// primaryimmune.org/about-primary-immunodeficiency-diseases/idfpublications?aid=1266\&pid=275\&sa=1. Accessed April 2, 2012.

29. Nicolay U, Kiessling P, Berger M, et al. Health-related quality of life and treatment satisfaction in North American patients with Primary Immunedefiency Diseases receiving subcutaneous IgG self-infusions at home. J Clin Immunol. 2006;26:65-72.

30. Bayrakci B, Ersoy F, Sanal O, et al. The efficacy of immunoglobulin replacement therapy in the long-term follow-up of the B-cell deficiencies. Turk J Pediatr. 2005;47:239-246.

31. Busse PJ, Razvi S, Cunningham-Rundles C. Efficacy of intravenous immunoglobulin in the prevention of pneumonia in patients with common variable immunodeficiency. J Allergy Clin Immunol. 2002;109:1001-1004.

32. Liese JG, Wintergerst U, Tympner KD, Belohradsky BH. High- vs lowdose immunoglobulin therapy in the long-term treatment of X-linked agammaglobulinemia. Am J Dis Child. 1992;146:335-339.

33. Nolte MT, Pirofsky B, Gerritz GA, Golding B. Intravenous immunoglobulin therapy for antibody deficiency. Clin Exp Immunol. 1979;36:237-243.

34. Pourpak Z, Aghamohammadi A, Sedighipour L, et al. Effect of regular intravenous immunoglobulin therapy on prevention of pneumonia in patients with common variable immunodeficiency. J Microbiol Immunol Infect. 2006;39:114-120.

35. Roifman CM, Lederman HM, Lavi S, Stein LD, Levison H, Gelfand EW. Benefit of intravenous IgG replacement in hypogammaglobulinemic patients with chronic sinopulmonary disease. Am J Med. 1985;79:171-174.

36. Chapel HM, Spickett GP, Ericson D, Engl W, Eibl MM, Bjorkander J. The comparison of the efficacy and safety of intravenous versus subcutaneous immunoglobulin replacement therapy. J Clin Immunol. 2000;20:94-100.

37. Berger M, Murphy E, Riley P, Bergman GE; VIRTUE Trial Investigators. Improved quality of life, immunoglobulin $\mathrm{G}$ levels, and infection rates in patients with primary immunodeficiency disease during self-treatment with subcutaneous immunoglobulin G. South Med J. 2010;103(9):856-863.

38. Hagan JB, Fasano MB, Spector S, et al. Efficacy and safety of a new $20 \%$ immunoglobulin preparation for subcutaneous administration, IgPro20, in patients with primary immunodeficiency. J Clin Immunol. 2010;30:734-745.

39. Jolles S, Bernatowska E, de Gracia J, et al. Efficacy and safety of Hizentra $^{\circledR}$ in patients with primary immunodeficiency after a doseequivalent switch from intravenous or subcutaneous replacement therapy. Clin Immunol. 2011;141:90-102.

40. Wasserman RL, Melamed I, Kobrynski L, et al. Efficacy, safety and pharmacokinetics of a $10 \%$ liquid immune globulin preparation (GAMMAGARD LIQUID, 10\%) administered subcutaneously in subjects with primary immunodeficiency disease. J Clin Immunol. 2011;31:323-331.

41. Orange JS, Grossman WJ, Navickis RJ, Wilkes MM. Impact of trough $\mathrm{IgG}$ on pneumonia incidence in primary immunodeficiency: a metaanalysis of clinical studies. Clin Immunol. 2010;137:21-30.

42. Lucas M, Lee M, Lortan J, et al. Infection outcomes in patients with common variable immunodeficiency disorders: relationship to immunoglobulin therapy over 22 years. J Allergy Clin Immunol. 2010;125:1354-1360.

43. Eijkhout HW, van Der Meer JW, Kallenberg CG, et al. The effect of two different dosages of intravenous immunoglobulin on the incidence of recurrent infections in patients with primary hypogammaglobulinemia. A randomized, double-blind, multicenter crossover trial. Ann Intern Med. 2001;135(3):165-174.

44. Roifman CM, Levison H, Gelfand EW. High-dose versus low-dose intravenous immunoglobulin in hypogammaglobulinemia and chronic lung disease. Lancet. 1987;1(8541):1075-1077.
45. Shehata N, Palda V, Bowen T, et al. The use of immunoglobulin therapy for patients with primary immune deficiency: an evidence-based practice guideline. Transfus Med Rev. 2010;24:S28-S50.

46. Quartier P, Debré M, De Blic J, et al. Early and prolonged intravenous immunoglobulin replacement therapy in childhood agammaglobulinemia: a retrospective survey of 31 patients. J Pediatr. 1999;134:589-596.

47. Roifman CM, Schroeder H, Berger M, et al. Comparison of the efficacy of IGIV-C, $10 \%$ (caprylate/chromatography) and IGIV-SD, 10\% as replacement therapy in primary immune deficiency. A randomized doubleblind trial. Int Immunopharmacol. 2003;3:1325-1333.

48. Berger M. Principles of and advances in immunoglobulin replacement therapy for primary immunodeficiency. Immunol Allergy Clin North Am. 2008;28(2):413-437.

49. Bonagura VR, Marchlewski R, Cox A, Rosenthal DW. Biologic IgG level in primary immunodeficiency disease: the IgG level that protects against recurrent infection. J Allergy Clin Immunol. 2008;122(1):210-212.

50. Cunningham-Rundles $C$. How I treat common variable immune deficiency. Blood. 2010;116:7-15.

51. Berger M. Incidence of infection is inversely related to steady-state (trough) serum IgG level in studies of subcutaneous IgG in PIDD. J Clin immunol. 2011;31:924-926.

52. Khan S, Grimbacher B, Boecking C, et al. Serum trough IgG level and annual intravenous immunoglobulin dose are not related to body size in patients on regular replacement therapy. Drug Metab Lett. 2011;5:132-136.

53. Berger M, Rojavin M, Kiessling P, Zenker O. Pharmacokinetics of subcutaneous immunoglobulin and their use in dosing of replacement therapy in patients with primary immunodeficiencies. Clin Immunol. 2011;139:133-141.

54. Quinti I, Soresina A, Guerra A, et al. Effectiveness of immunoglobulin replacement therapy on clinical outcome in patients with primary antibody deficiencies: results from a multicenter prospective cohort study. J Clin Immunol. 2011;31:315-322.

55. Chapel H, Cunningham-Rundles C. Update in understanding common variable immunodeficiency disorders (CVIDs) and the management of patients with these conditions. Br J Haematol. 2009;145:709-727.

56. Roifman CM, Berger M, Notarangelo LD. Management of primary antibody deficiency with replacement therapy: summary of guidelines. Immunol Allergy Clin North Am. 2008;28(4):875-876.

57. Yong PI, Boyle J, Ballow M, et al. Use of intravenous immunoglobulin and adjunctive therapies in the treatment of primary immunodeficiencies. A working group report of and study by the Primary Immunodeficiency Committee of the American Academy of Allergy, Asthma and Immunology. Clin Immunol. 2010;135(2):255-263.

58. Gardulf A, Bjorvell H, Gustafson R, et al. Safety of rapid subcutaneous gamma-globulin infusions in patients with primary antibody deficiency. Immunodeficiency. 1993;4:81-84.

59. Gaspar J, Gerritsen B, Jones A. Immunoglobulin replacement treatment by rapid subcutaneous infusion. Arch Dis Child. 1998;79:48-51.

60. Hansen S, Gustafson R, Smith CI, Gardulf A. Express subcutaneous IgG infusions: decreased time of delivery with maintained safety. Clin Immunol. 2002;104:237-241.

61. Shapiro R. Subcutaneous immunoglobulin therapy by rapid push is preferred to infusion by pump: a retrospective analysis. J Clin Immunol. 2010;30:301-307.

62. Berger M. Subcutaneous administration of IgG. Immunol Allergy Clin North Amer. 2008;28(4):779-802.

63. Gamunex-c.com [homepage on the Internet]. Gamunex-C PI SubQ Infusion Video. USA: Talecris Biotherapeutics; 2010. Available from: http://www.gamunex-c.com/patient-connexions-support-patienteducation-PI.htm. Accessed April 30, 2012.

64. Gammagard.com [homepage on the Internet]. How to infuse: subcutaneous administration of Gammagard liquid. Westlake Village, CA: Baxter Healthcare Corporation; 2011. Available from: http://www.gammagard. $\mathrm{com} /$ patients-and-families/help-for-patients/patient-education.html. Accessed April 30, 2012. 
65. hizentra.com [homepage on the Internet]. Self-Administration Video. Kankakee, IL: CSL Behring, LLC; 2010. Available from: www.hizentra. com/consumer/about-hizentra/sub-q-self-administration-video.aspx. Accessed April 30, 2012.

66. primaryimmune.org [homepage on the Internet]. Online accredited course for nurses about primary immunodeficiency and immunoglobulin therapy. Towson, MD: Immune Deficiency Foundation; 2011. Available from: http://primaryimmune.org/2011/09/idf-launches-free-accreditedcourse-for-nurses-about-primary-immunodeficiency-and-immunoglobulin-therapy. Accessed April 30, 2012.

67. hizentra.com [homepage on the Internet]. SHARE nurse training. Kankakee, IL: CSL Behring, LLC; 2012. Available from: http://www. hizentra.com/share/default.aspx. Accessed April 30, 2012.

68. Berger M, Pinciaro PJ. Safety, efficacy, and pharmacokinetics of Flebogamma 5\% immune globulin intravenous (human) for replacement therapy in primary immunodeficiency diseases. J Clin Immunol. 2004;24(4):389-396

69. Church JA, Leibl H, Stein MR, et al. Efficacy, safety and tolerability of a new $10 \%$ liquid intravenous immune globulin (IGIV 10\%) in patients with primary immunodeficiency. J Clin Immunol. 2006;26:388-395.

70. Stein M, Nelson R, Church J, et al. Safety and efficacy of Privigen, a novel $10 \%$ liquid immunoglobulin preparation for intravenous use, in patients with primary immunodeficiencies. J Clin Immunol. 2009;29:137-144.

71. Wasserman R, Church J, Stein M, et al. Safety, efficacy and pharmacokinetics of a new 10\% liquid intravenous immunoglobulin (IVIG) in patients with primary immunodeficiency. J Clin Immunol. March 6, 2012. [Epub ahead of print.]

72. Brennan VM, Salome-Bentley NJ, Chapel HM. Prospective audit of adverse reactions occurring in 459 primary antibody-deficient patients receiving intravenous immunoglobulin. Clin Exp Immunol. 2003; $133: 247-251$.

73. Gardulf A, Anderson V, Bjorkander J, et al. Subcutaneous immunoglobulin replacement in patients with primary antibody deficiencies: safety and costs. Lancet. 1995;345(8946):365-369.

74. Radinsky S, Bonagura VR. Subcutaneous immunoglobulin infusion as an alternative to intravenous immunoglobulin. JAllergy Clin Immunol. 2003;112(3):630-633.

75. Epstein JS, Zoon KC. Dear doctor letter - important drug warning: immune globulin intravenous (human). FDA Med Watch. US Food and Drug Administration; 1998. Available from: http://www.fda.gov/ biologicsbloodvaccines/safetyavailability/ucm105914.htm. Accessed July 14, 2012.

76. Pierce LR, Jain N. Risks associated with the use of intravenous immunoglobulin. Transfusion Med Rev. 2003;17(4):241-251.

77. Dalakas MC. High-dose intravenous immunoglobulin and serum viscosity: risk of precipitating thromboembolic events. Neurology. 1994;44:223-226.

78. Daniel GW, Menis M, Sridhar G, et al. Immune globulins and thrombotic adverse events as recorded in a large administrative database in 2008 through 2010. Transfusion. March 12, 2012. [Epub ahead of print.]

79. Ovanesov MV. Laboratory investigations of products associated with thrombotic events. In: FDA Workshop: Risk Mitigation Strategies to Address Procoagulant Activity in Immune Globulin Products. Bethesda, MD; US Food and Drug Administration: 2011. Available from: http:// www.fda.gov/downloads/BiologicsBloodVaccines/NewsEvents/ WorkshopsMeetingsConferences/UCM260788.pdf. Accessed.

Biologics: Targets \& Therapy

\section{Publish your work in this journal}

Biologics: Targets \& Therapy is an international, peer-reviewed journal focusing on the patho-physiological rationale for and clinical application of Biologic agents in the management of autoimmune diseases, cancers or other pathologies where a molecular target can be identified This journal is indexed on PubMed Central, CAS, EMBase, Scopus
80. Nicolay U, Haag S, Eichmann F, Herget S, Spruck D, Gardulf A Measuring treatment satisfaction in patients with primary immunodeficiency diseases receiving lifelong immunoglobulin replacement therapy. Qual Life Res. 2005;14:1683-1691.

81. Fasth A, Nystrom J. Quality of life and health-care resource utilization among children with primary immunodeficiency receiving home treatment with subcutaneous human immunoglobulin. J Clin Immunol. 2008;28:370-378.

82. Kittner JM, Grimbacher B, Wulff W, Jäger B, Schmidt RE. Patients' attitude to subcutaneous immunoglobulin substitution as home therapy. J Clin Immunol. 2006;26:400-405.

83. Hoffmann F, Grimbacher B, Thiel J, Peter HH, Belohradsky BH; Vivaglobin Study Group. Home-based subcutaneous immunoglobulin $\mathrm{G}$ replacement therapy under real-life conditions in children and adults with antibody deficiency. Eur J Med Res. 2010;15(6):238-245.

84. Fasth A, Nystrom J. Safety and efficacy of subcutaneous human immunoglobulin in children with primary immunodeficiency. Acta Paediatrica. 2007;96:1474-1478.

85. Gardulf A, Andersson E, Lindqvist M, et al. Rapid subcutaneous IgG replacement therapy at home for pregnant immunodeficient women. J Clin Immunol. 2001;21:150-154.

86. Sundin U, Nava S, Hammarstrom L. Induction of unresponsiveness against IgA in IgA- deficient patients on subcutaneous immunoglobulin infusion therapy. Clin Exp Immunol. 1998;112:341-346.

87. Koller H, Schroeter M, Feischen H, Hartung HP, Kieseier BC. Subcutaneous self-infusions of immunoglobulins as a potential therapeutic regimen in immune-mediated neuropathies. $J$ Neurol. 2006;253(11):1505-1506.

88. Misbah S, Kuijpers T, van der Heijden J, Grimbacher B, Guzman D, Orange J. Bringing immunoglobulin knowledge up to date: how should we treat today? Clin Exp Immunol. 2011;166:16-25.

89. Knight E, Carne E, Novak B, et al. Self-administered hyaluronidasefacilitated subcutaneous immunoglobulin home therapy in a patient with primary immunodeficiency. J Clin Pathol. 2010;63:846-847.

90. Schiff RI, Wasserman R, Stein M, et al. Recombinant human hyaluronidase facilitates dispersion of subcutaneously administered gammagard liquid, enabling administration of full monthly dose in single site with improved bioavailability in immunodeficient patients [abstract]. Clin Exp Immunol. 2008;154(Suppl 1):121.

91. Melamed IR, Stein MR, Wasserman RL, et al. Recombinant human hyaluronidase facilitates dispersion of subcutaneously administered Gammagard liquid and enables administration of a full monthly dose in a single site to patients with immunodeficiency diseases [abstract]. J Allergy Clin Immunol. 2008;121(2 Suppl 1):S83.

92. Stein M, Wasserman RL, Melamed I, et al. Pharmacokinetics (PK) of human immunoglobulin $10 \%$ ( $\mathrm{IgG}$ ) administered intravenously (IGIV), subcutaneously (IGSC) or facilitated subcutaneously with recombinant human hyaluronidase (IGHy) in a subset of patients with Primary Immunodeficiency Disease (PIDD). J Allergy Clin Immunol. 2012;29:AB14.

93. Wasserman RL, Melamed I, Stein M, et al. Tolerability and efficacy of facilitated-subcutaneous infusion of immune globulin (Human), 10\% and recombinant human hyaluronidase (IGHy) in a subset of study patients with Primary Immunodeficiency Disease (PIDD). $J$ Allergy Clin Immunol. 2012;29:AB15.

\section{Dovepress}

and the Elsevier Bibliographic databases. The manuscript management system is completely online and includes a very quick and fair peerreview system, which is all easy to use. Visit http://www.dovepress. $\mathrm{com} /$ testimonials.php to read real quotes from published authors. 